\title{
COMPUTER KNOWLEDGE ON THE DECISION SUPPORT CAPABILITIES OF INTERACTIVE ANALYTICAL DASHBOARD
}

\author{
Bih-Ru Lea, Missouri University of Science \& Technology, leabi@mst.edu \\ Wen-Bin Vincent Yu, Missouri University of Science \& Technology,yuwen@mst.edu \\ Hokey Min, Bowling Green State University,hmin@bgsu.edu
}

\begin{abstract}
This research investigates whether a user's computer knowledge has influence on the decision support capabilities of an interactive analytical dashboard to harness the power of data for timely and more informed decisions. The computer knowledge is expressed as a self-rated IT knowledge level and the number of computer classes a user had. Results have indicated that the user's IT knowledge level and the number of computer classes a user had do not significantly influences the effectiveness and efficiency of an interactive analytical dashboard for its decision support capabilities. This finding is important as it implies that analytical dashboards can be easily and adopted used by novice business users to support decision making regardless of a user's computer knowledge.
\end{abstract}

Keywords: Analytical Dashboard, Computer Knowledge, Decision Support.

\section{INTRODUCTION}

Opportunities and challenges of advanced business analytics are studied and documented by Bose (2009) and Wang, et al. (2015). Min (2016) noted that if the results presented by business analytics cannot be easily translated into the decision maker's terms, those results may be misunderstood or misinterpreted and thus may lead to the wrong decision. As such, the simplification of analytics results through interactive dashboards or data visualizations is essential for creating meaningful business intelligence that can help a decision maker understand the significance of data in a visual context.

The interactive analytical dashboard can easily expose and recognize the patterns, trends and correlations, so a welldesigned dashboard can help users gain insights into their data and support decision making processes effectively and efficiently (Lea, 2011; Elias and Bezerianos, 2012; Lea \& Nah, 2013). As such, an interactive analytical dashboard has received a wider attention from many workplaces, especially business executives and managers who have to deal with abundant data for their routine decision making processes (Lea, 2011).

Although a picture is worth a thousand words, the same visualizations and graphical results may not be interpreted in the same manner, if the user's knowledge bases are different. For example, a statistician with a higher computer literacy is likely to be able to better understand and interpret complex graphical results (e.g., statistical charts and decision trees) than a person with a limited education and computer background. Under such an underlying premise, since the user knowledge can be influenced by the user's demographic profiles (e.g., country of origin) and educational experiences (e.g., number of computer classes taken, and school year), this research exams influence of a user's computer knowledge on the decision support capabilities of an interactive analytical dashboard.

\section{LITERATURE REVIEW}

Despite the growing popularity of interactive analytical dashboards, the extent of their impact on decision support capabilities has been rarely studied in the published literature. To fill that void left by prior studies, this paper aims to shed light on the usefulness of interactive analytical dashboards for decision support and to gain insights into various factors that influence the effectiveness and efficiency of data visualization tools. 
In the domain of Business Intelligence (BI) analysis, the most popular visualization tools are dashboards (Elias \& Bezerianos, 2012). A dashboard is often defined as a multilayered interactive visual display built on business intelligence and the data integration infrastructure that conveys key information on a single screen to allow users to effectively measure, monitor, and manage business performance of an organization toward predefined goals (Eckerson, 2011, Lea, 2011; Few, 2013; Lea, et. al., 2018). As such, analytical dashboards often have multiple interactive visualization objects that require a high capacity Graphical Processing Unit (GPU) and the adequate screen display area. Lea and $\mathrm{Yu}$ (2017) reported that the types of devices used for dashboard access influences the capabilities of dashboard on decision support (Lea \& Yu 2017).

An interactive analytical dashboard provides an easy to use graphical interface, requires minimum or no user training, has capabilities to monitor progress towards performance objectives visually, and aims to improve communication and information sharing. The expected benefits of dashboards include improving the entity's ability to quickly monitor progress in achieving goals, enhancing efficiency in responding to business events, and improving planning (Eckerson, 2011; Bremser \& Wagner, 2013). By integrating data from multiple sources, dashboards are able to transform data into actionable information. With its ability to consolidate and transform data into metrics, the dashboards are able to present the right information to the right users by allowing users to drill-down or drill-across their areas of interest (Brooks et al., 2006). The drill-down and drill-across functionality allows the business users to build their own reports that are customized to meet their requirements, thus reduce their dependence on the IT professional and minimize information delay to save a significant amount of time (Brooks, 2006).

User demographic factors were reported to affect technologies adoption and learning in prior studies. Researchers found that the user' age differences could affect his/her behavior toward the technology use (Loyd \& Gressard, 1984; Morris \& Venkatesh, 2000; Fatemifar, et al., 2015). Many researchers theorized that gender differences might have a significant impact on the person's technology adoption and usage (Loyd \& Gressard, 1984; Badagliacco, 1990; Gefen \& Straub, 1997; Parameswaran, et. al. 2015). Findings on self-rated computer knowledge or experience on technology adoption and learning performance were inconclusive. Loyd and Gressard (1984), Potosky (2000), and Hatlevik, et al. (2018) reported that self-rated computer knowledge positively correlated with learning performance while Wells (2000) found no support of computer knowledge on student learning performance. Moos and Azevedo (2009) suggested that the relationship between self-rated computer knowledge and learning may change as students acquire knowledge. Wawrzynski (2003) reported influence of academic experience on technology adoption and learning performance. Therefore, the number of computer class a user has taken may serve as an indicator of a user's computer knowledge.

\section{RESEARCH OBJECTIVES, QUESTIONS, AND METHODOLOGY}

Prior studies reported that a user's computer knowledge influences learning outcomes and technology adoptions (Loyd \& Gressard, 1984; Potosky, 2000; Lea \& Yu, 2017; Hatlevik, et. al., 2018; Wawrzynski, 2003). As dashboards often require minimal or no user training (Eckerson, 2011, Lea \& Nah, 2013; Lea \& Yu, 2017), dashboards aim to allow both IT-savvy and non-IT users to improve decision making quality (Lea \& Nah, 2013). That is, it implies that dashboards can be easily used by a user to support decision making regardless of a user's computer knowledge. However, research effort has not been devoted to investigate the claim that a user's computer knowledge has no influence on the use of analytical dashboards in decision support.

As an extension to the prior literature, the objective of this research is to investigate if a user's computer knowledge has significant influence on the efficiency and effectiveness of interactive analytical dashboard for their decision support capabilities. This research hypothesizes that a user's computer knowledge has no significant influence on the efficiency and effectiveness of interactive analytical dashboards for their decision support capabilities. A user's computer knowledge is represented by two independent variables: a user self-rated IT knowledge level and the number of computer classes taken. The decision support capabilities are measured by effectiveness and efficiency. The efficiency is measured by a completion rate that is computed as a number of questions attempted divided by the total number of questions in the study. The effectiveness is measured by an accuracy rate that is computed as the number of questions answered correctly divided by the number of questions. 
Following research hypotheses are derived to answer the proposed research question:

Hypothesis 1: A user's IT knowledge level has no influence on the decision support capabilities of an interactive dashboard $\left(\mathrm{H}_{0}\right.$ : IT_Knowledge $\left.=0\right)$

Hypothesis 2: The number of computer classes a user had does not significantly influence the decision support capabilities of an interactive dashboard $\left(\mathrm{H}_{0}\right.$ : Computer_Classes $\left.=0\right)$

Hypothesis 3: There influences on the decision support capabilities of an interactive dashboard will not differ based on a user's IT knowledge level and the number of computer classes a user had $\left(\mathrm{H}_{0}\right.$ : IT_Knowledge $\mathrm{X}$ Computer Classes $=0$ )

The proposed research model is expressed as the following equation form:

$$
\mathrm{Y}_{\mathrm{i}, \mathrm{j}, \mathrm{k}}=\mu+\mathrm{IT}_{-} \text {Knowledge }_{\mathrm{i}, \mathrm{j}}+\text { Computer_Classes }_{\mathrm{i}, \mathrm{k}}+\varepsilon
$$

Where:

$\mathrm{Y}_{\mathrm{i}}: \mathrm{i}=1,2 . \mathrm{Y}_{1}$ is Completion Rate and $\mathrm{Y}_{2}$ is the Accuracy Rate

IT_Knowledge $e_{i, j}$ : User self-rated IT knowledge in a scale of 1 to $10 . j=$ Low (scale 1 to 4 ),

Average (scale 5 to 7 ), and High (scale 8 to 10 ).

Computer_Classes $\mathrm{i}, \mathrm{k}=$ the number of computer courses that a user had. $\mathrm{k}=0$ to 1,2 to 3,4 to 5 , and 6 or more.

$\varepsilon=$ the error term.

An interactive analytical dashboard app was developed using HTML5 for display across different devices. Although hybrid apps can be used on devices of different platforms, the HTML 5 web app is selected for this research as it is the most commonly used format among the three mobile app types while reducing installation and setup time needed for the experiment. The dashboard was implemented using the SAP Design Studio extracting data via a set of queries from an SAP HANA data warehouse.

The dashboard was designed for a simple business scenario, so experiment participants can easily relate and understand the business case during the experiment. Figure 1 illustrates the analytical dashboard. The business scenario is to keep employees of a hypothetical company DD aware of their products and sales as well as product and sales from their competitors (i.e., AA, BB, CC, and EE in Figure 1). The first tab contains two tables, one showing revenues for companies AA to EE and the revenue for each product that those companies produce. The second tab contains an overview of all products that company DD produced. When one is selected, the participant will be able to see a breakdown of the different materials that make up that product, and the overall cost of each material. The dashboard went through several iterations and usability tests to ensure that it was ready for experimentations during a period of eight months. 


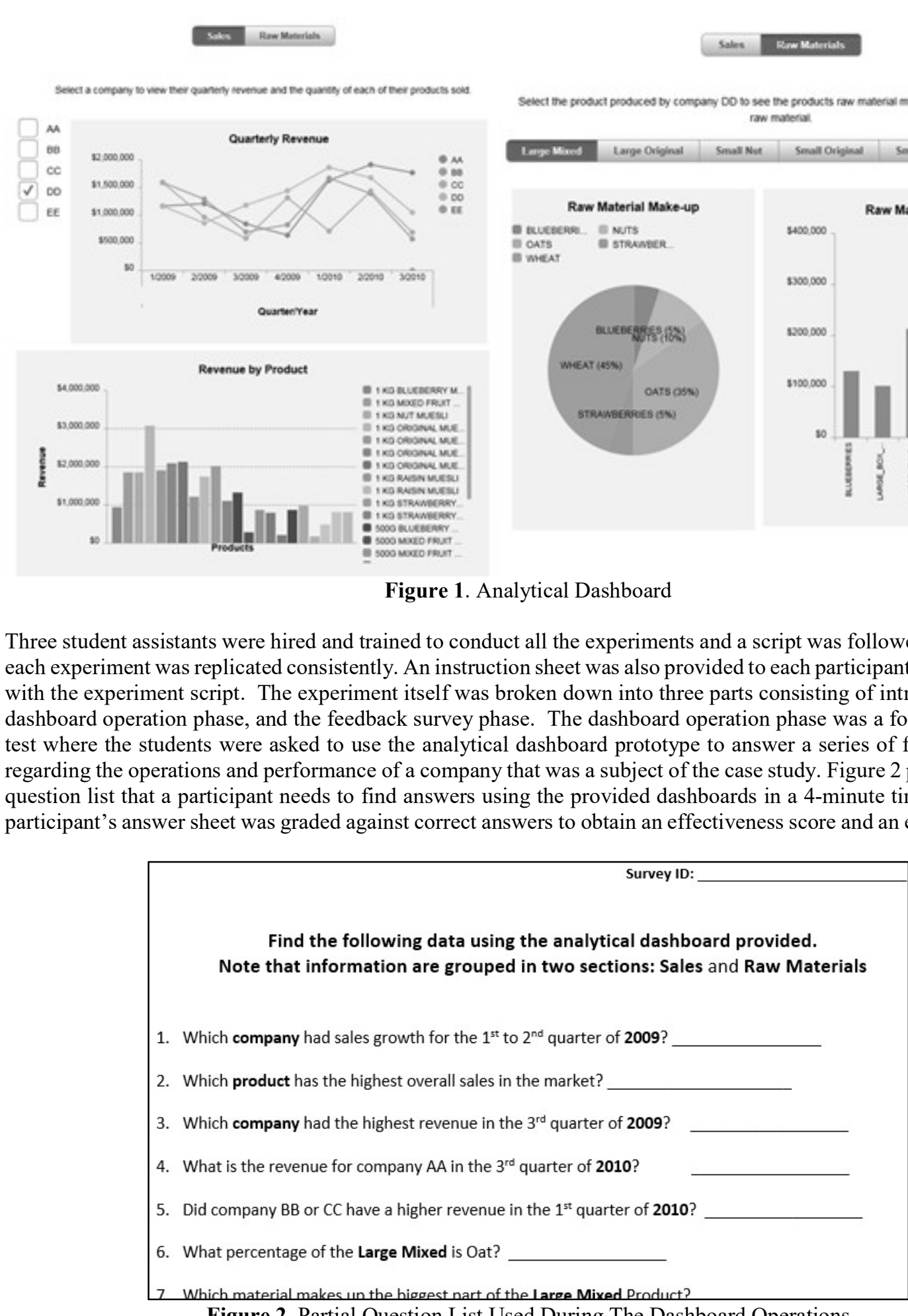

Figure 2. Partial Question List Used During The Dashboard Operations 


\section{RESULTS AND DISCUSSIONS}

The data were collected from eight different classes in three program areas of Information Science and Technology (IST), Business (BUS), and Enterprise Resource Planning (ERP) in the Department of Business and Information Technology in a university located in the Midwest of the United States. Four classes had both the in-class session and the distance learning session. Distance learning students were not required to attend a class live and most distance learning students choose to watch recorded classes. Participation in the experiment was optional and a student can choose to opt out from the experiment. A student can only participate in the experiment when he/she attended a class on the experiment day and the experiment date was not announced to students in advance. Although the same student may take several classes among the eight classes where the experiment was conducted, a student can only participate in the experiment once. As a result, 152 undergraduate and graduate students among 269 enrolled in the eight classes participated in this experiment.

Figure 3 summarizes the detailed distribution of self-reported level of IT Knowledge, and the number of computer courses taken by the students participated in this experiment.
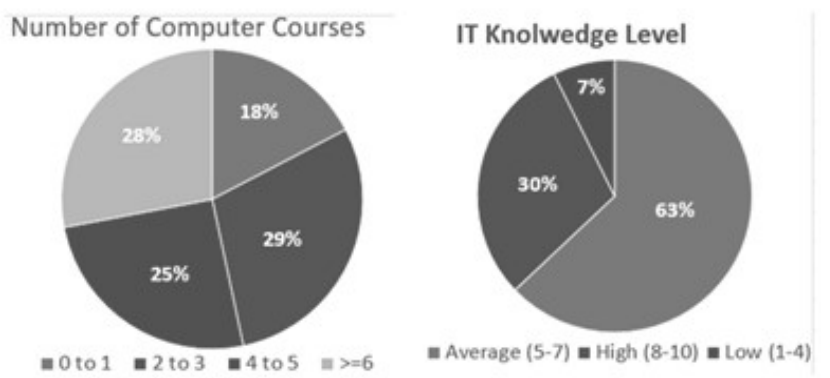

Figure 3. Distributions of the Participants on the IT Knowledge level and Number of computer courses taken

Table 1. Dashboard Usability Test

\begin{tabular}{|c|c|c|c|c|c|c|c|c|c|c|}
\hline \multirow{3}{*}{ Assessment Statement } & \multirow{3}{*}{$\mathbf{N}$} & \multirow{3}{*}{ Mean } & \multirow{3}{*}{$\begin{array}{c}\text { Std. } \\
\text { Deviation }\end{array}$} & \multirow{3}{*}{$\begin{array}{c}\text { Std. Error } \\
\text { Mean }\end{array}$} & \multicolumn{6}{|c|}{ Test Value $=3$} \\
\hline & & & & & \multirow[t]{2}{*}{$\mathbf{t}$} & \multirow[t]{2}{*}{ df } & \multirow{2}{*}{$\begin{array}{l}\text { Sig. (2- } \\
\text { tailed) }\end{array}$} & \multirow{2}{*}{$\begin{array}{c}\text { Mean } \\
\text { Difference }\end{array}$} & \multicolumn{2}{|c|}{$\begin{array}{c}95 \% \\
\text { Confidence }\end{array}$} \\
\hline & & & & & & & & & Lower & Upper \\
\hline I can easily learn to use the dashboard & 152 & 4.15 & 0.761 & 0.062 & 18.645 & 151 & 0.000 & 1.151 & 1.03 & 1.27 \\
\hline $\begin{array}{l}\text { The dashboard helped me analyzing } \\
\text { sales, materials, and costs. }\end{array}$ & 152 & 3.87 & 0.911 & 0.074 & 11.750 & 151 & 0.000 & 0.868 & 0.72 & 1.01 \\
\hline $\begin{array}{l}\text { The dashboard provided data to identify } \\
\text { the case company's areas of } \\
\text { improvement }\end{array}$ & 152 & 3.66 & 0.929 & 0.075 & 8.735 & 151 & 0.000 & 0.658 & 0.51 & 0.81 \\
\hline $\begin{array}{l}\text { The dashboard provided trends to } \\
\text { analyze and compare data from } \\
\text { previous year and with competitors }\end{array}$ & 152 & 4.03 & 0.853 & 0.069 & 14.832 & 151 & 0.000 & 1.026 & 0.89 & 1.16 \\
\hline $\begin{array}{l}\text { The dashboard provided a clear } \\
\text { understanding of the case company } \\
\text { and its available data }\end{array}$ & 152 & 3.76 & 1.002 & 0.081 & 9.394 & 151 & 0.000 & 0.763 & 0.60 & 0.92 \\
\hline I am comfortable using this dashboard & 152 & 3.83 & 0.912 & 0.074 & 11.208 & 151 & 0.000 & 0.829 & 0.68 & 0.98 \\
\hline $\begin{array}{l}\text { The dashboard provided relevant } \\
\text { information to help me making decision }\end{array}$ & 151 & 3.89 & 0.810 & 0.066 & 13.571 & 150 & 0.000 & 0.894 & 0.76 & 1.02 \\
\hline $\begin{array}{l}\text { The dashboard has a user-friendly } \\
\text { interface }\end{array}$ & 151 & 3.71 & 1.043 & 0.085 & 8.349 & 150 & 0.000 & 0.709 & 0.54 & 0.88 \\
\hline
\end{tabular}

Table 2 provided the results of dashboard usability test based on eight selected dimensions on a Liker scale of 1 (strongly disagree) to 5 (strongly agree) from all participants. All assessment values are greater than 3 and those values indicated that participants were comfortable with the dashboards. As the results indicated, the dashboard was easy to learn, has a user-friendly interface, helped the students analyze data, identify the areas of improvement for the case company while providing the trends of comparative data needed for decision making. A mean comparison test was 
conducted and results indicate no difference in a user's perceived dashboard usability among users with different IT knowledge levels or among users with different number of computer classes, as shown in Table 2.

Table 2. Dashboard Usability Test on a User's IT Knowledge Levels and Number of Computer Classes

\begin{tabular}{|c|c|c|c|c|c|c|c|c|c|c|}
\hline \multirow[b]{2}{*}{ Usability Measures } & \multicolumn{5}{|c|}{ IT Knowledge Level } & \multicolumn{5}{|c|}{ Number of Computer Classes } \\
\hline & \begin{tabular}{|l|}
$\begin{array}{l}\text { Type III Sum } \\
\text { of Squares }\end{array}$ \\
\end{tabular} & df & \begin{tabular}{|l|} 
Mean \\
Square
\end{tabular} & $\mathrm{F}$ & Sig. & \begin{tabular}{|l|}
$\begin{array}{l}\text { Type III Sum } \\
\text { of Squares }\end{array}$ \\
\end{tabular} & $\mathrm{df}$ & \begin{tabular}{l|} 
Mean \\
Square
\end{tabular} & $\mathrm{F}$ & Sig. \\
\hline I can easily learn to use the dashboard & $\begin{array}{r}1.625 \\
\end{array}$ & 2 & 0.812 & 1.5170 & 0.2230 & 3.12 & 3 & 1.04 & 1.9420 & 0.1260 \\
\hline $\begin{array}{l}\text { The dashboard provided data to identify the } \\
\text { case company's areas of improvement }\end{array}$ & 7.073 & 2 & 3.537 & 4.3810 & 0.0140 & 2.995 & 3 & 0.998 & 1.2370 & 0.2990 \\
\hline $\begin{array}{l}\text { The dashboard provided a clear understanding } \\
\text { of the case company and its available data }\end{array}$ & 1.965 & 2 & 0.982 & 1.1060 & 0.3340 & 6.526 & 3 & 2.175 & 2.4500 & 0.0660 \\
\hline
\end{tabular}

The perceived dashboard usability does not change by a user's computer knowledge or by the number of computer classes a user had, the multivariate General Liner model was then conducted to analyze the experimental results. As results shown in Table 3, there is insufficient evidence to reject the three null hypotheses at $\alpha=0.05$ level. That is, a user's self-rated IT Knowledge, the number of computer classes a user had, and their interactions do not significantly influence the effectiveness (accuracy rate) and the efficiency (completion rate) of analytical dashboards at $\alpha=0.05$ level.

Table 3. Partial Tests of Between-Subjects Effects

\begin{tabular}{|c|c|c|c|c|c|c|}
\hline \multicolumn{2}{|c|}{ Source } & $\begin{array}{c}\text { Type III Sum } \\
\text { of Squares }\end{array}$ & df & $\begin{array}{c}\text { Mean } \\
\text { Square }\end{array}$ & $\mathbf{F}$ & Sig. \\
\hline \multirow{2}{*}{ Corrected Model } & Accuracy_Rate & $.334^{\mathrm{a}}$ & 9 & 0.037 & 1.145 & 0.335 \\
\hline & Completion_Rate & $.285^{\mathrm{b}}$ & 9 & 0.032 & 0.616 & 0.782 \\
\hline \multirow{2}{*}{ Intercept } & Accuracy_Rate & 46.274 & 1 & 46.274 & 1428.599 & 0.000 \\
\hline & Completion_Rate & 19.373 & 1 & 19.373 & 376.867 & 0.000 \\
\hline \multirow{2}{*}{ IT_Knowledge } & Accuracy_Rate & 0.159 & 2 & 0.079 & 2.449 & $0.090 *$ \\
\hline & Completion_Rate & 0.004 & 2 & 0.002 & 0.041 & 0.960 \\
\hline \multirow{2}{*}{ Computer_Classes } & Accuracy_Rate & 0.001 & 3 & 0 & 0.013 & 0.998 \\
\hline & Completion_Rate & 0.01 & 3 & 0.003 & 0.067 & 0.977 \\
\hline \multirow{2}{*}{$\begin{array}{l}\text { IT_Knowledge * } \\
\text { Computer_Classes }\end{array}$} & Accuracy_Rate & 0.08 & 4 & 0.02 & 0.615 & 0.653 \\
\hline & Completion_Rate & 0.224 & 4 & 0.056 & 1.088 & 0.365 \\
\hline \multirow{2}{*}{ Error } & Accuracy_Rate & 4.535 & 140 & 0.032 & & \\
\hline & Completion_Rate & 7.197 & 140 & 0.051 & & \\
\hline
\end{tabular}

* significant at $\alpha=0.09$ level

a. R Squared $=.069($ Adjusted R Squared $=.009) \quad$ b. R Squared $=.038($ Adjusted R Squared $=-.024)$

With a p-value of 0.09 , results from the influence of a user self-rated IT knowledge level on the dashboard decision support capability measured by accuracy rate is not as conclusive as other factors. Therefore, further analyses were performed to gain additional insights.

The decision tree analysis was conducted and results are shown in Figure 4. Users with a self-rated "Average" IT knowledge level were more effective in using an interactive analytical dashboard for decision support than those who ranked themselves a "Low" or "High" IT knowledge level. To elaborate, according to the decision tree model that 
was developed to derive decision rules, the rule of users with an average IT knowledge level applies to $63 \%$ of records in the data set and the average accuracy rate for those records was $84 \%$ with a standard deviation of 0.17 . The rule of users with a low or high self-rated IT knowledge level applies to $37 \%$ of records and the average accuracy rate for those records was $77 \%$ with a standard deviation of 0.19 .

\section{The decision tree shows how Accuracy_Rate is influenced by IT Knowledge level.}

These two decision rules predict the highest Accuracy_Rate values.

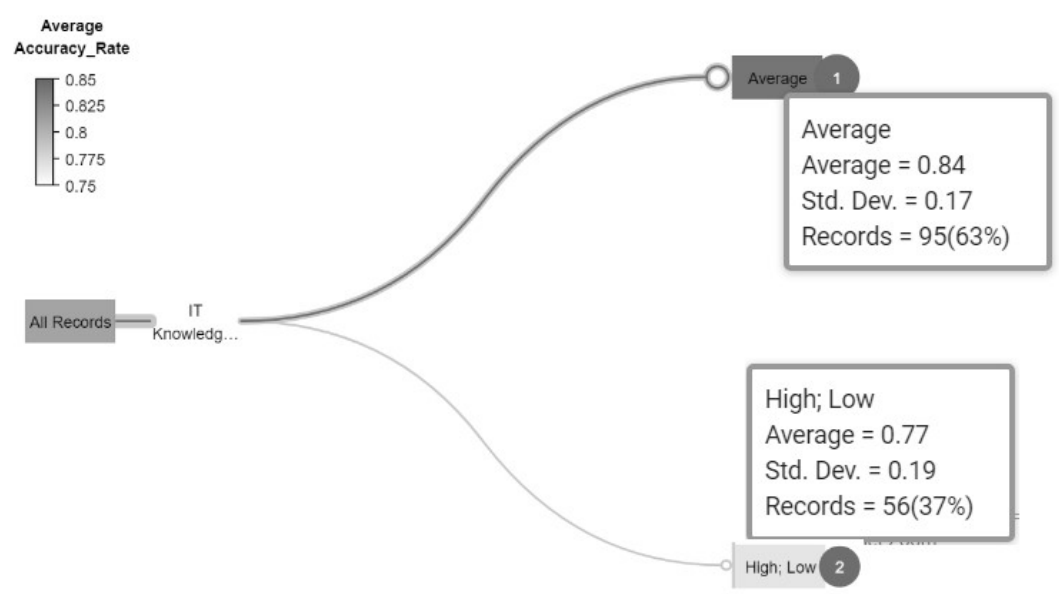

Figure 4. Decision Tree Analysis of IT Knowledge Level Influence on Dashboard Decision Support Effectiveness

Regression analysis was then conducted to investigate relation between a self-rated IT knowledge level and the number of computer classes and results are shown in Table 4. The regression model indicated that a user's self-rated IT knowledge level increases as a student completed more computer classes. This observation is consistent with findings of Moos and Azevedo (2009) that the relationship between self-rated computer knowledge and learning may change as students acquire knowledge.

Table 4. Regression analysis Partial Tests of Between-Subjects Effects ANOVA*

\begin{tabular}{|c|c|c|c|c|c|}
\hline Model & Sum of Squares & df & Mean Square & $\mathrm{F}$ & Sig. \\
\hline Regression & $\begin{array}{r}85.681 \\
\end{array}$ & 1 & $\begin{array}{r}85.681 \\
\end{array}$ & 31.821 & $0.000 * *$ \\
\hline Residual & 401.194 & 149 & 2.693 & & \\
\hline Total & 486.874 & 150 & & & \\
\hline \multicolumn{6}{|c|}{ * Dependent Variable: IT_Knowledge } \\
\hline \multicolumn{6}{|c|}{ *** Predictors: (Constant), Computer_Classes } \\
\hline Model* & Coefficients (B) & Std. En & $\mathrm{t}$ & Sig. & \\
\hline (Constant) & 4.709 & 0.357 & 13.191 & 0.000 & \\
\hline Computer_Cl & 0.705 & 0.125 & 5.641 & 0.000 & \\
\hline * Dependent V & Variable: IT_Know & vledge & & & \\
\hline
\end{tabular}

As shown in Figure 4, students who had more computer classes tended to rank themselves with a higher level of IT knowledge, but do not score a higher accuracy rate than the students with average IT knowledge level, as shown in Figure 5. On the other hand, students who took very few or no computer classes but self-rated a high IT knowledge level had the lowest accuracy rate and that might signal a self-inflated IT knowledge level. 
Issues in Information Systems

Volume 19, Issue 4, pp. 140-149, 2018

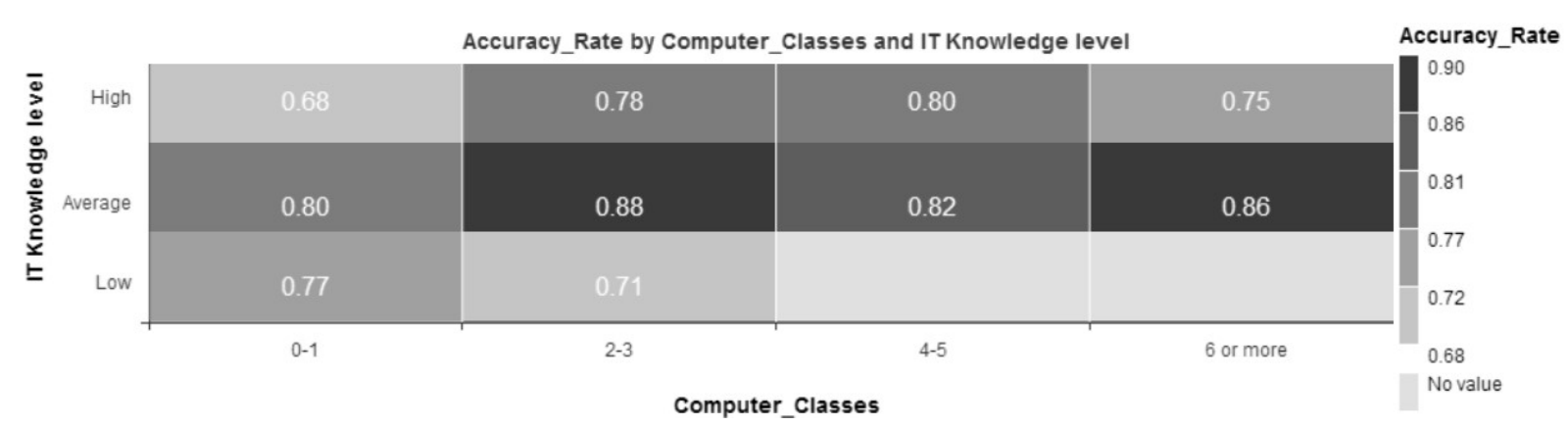

Figure 5. Accuracy Rate (Effectiveness) by Number of Computer Classes \& IT Knowledge Level

\section{CONCLUSION AND FUTURE RESEARCH DIRECTIONS}

Research examining the effectiveness and efficiency of decision support tools in today's commerce environments is scarce (Chen, et al, 2012). To fill this research gap, this research initiated the new line of research investigating the influence of a user's computer knowledge on the decision support capabilities of an interactive analytical dashboard. The study findings summarized above have important practical implications for nurturing future business analysts and decision makers for many reasons. First, the results indicated that a user's IT knowledge level, the number of computer classes a user had, and their interactions do not significantly affect the efficiency of interactive analytical dashboards for their decision support capabilities. As the efficiency is measured by the completion rate, the results indicated that a user with a higher IT knowledge level or had more computer classes can perform tasks as fast as a user with a lower IT knowledge level or had fewer computer classes. As users were using the dashboard for the first time, the easy to learn and a friendly user interface features are likely the contributing factors that allow users to learn and operate the dashboard with minimal or no training. One important business implication of this finding is that an analytical dashboard can serve as an effective decision support tool for novice and less IT-savvy business users such as sales representatives, human resource employees, and managers.

On the other hand, a user's self-rated IT knowledge level has some influence on the on the effectiveness of using an analytical dashboard as a decision support tool. As effectiveness is measured by the accuracy rate in this study, results indicated that a user with an average IT knowledge level made more accurate decisions than a user with a lower or a higher IT knowledge level when an analytical dashboard is used. Although it is not unexpected that a user with a lower IT knowledge level made less accurate decisions, additional research is needed to identify causes of the lower decision accuracy from users who had more computer classes and a high self-rated IT knowledge level.

Consistent with findings of Moos and Azevedo (2009), results of this research supports that a user's self-rated computer knowledge level increases as a user acquires knowledge through taking more computer classes. As a user's self-rated IT knowledge level has influence on the decision accuracy, one implication of this finding is that a user can improve decision accuracy by taking more computer classes.

Additional researches that include demographic factors such as gender and ethnicity can be useful. As decision accuracy may be influenced by a user's subject knowledge and reasoning skills, studies that include a user's major and mathematical skill are useful. Furthermore, additional experiments with much larger subjects and more diverse performance metrics would be fruitful as the future research agenda.

\section{REFERENCES}

Badagliacco, J. M. (1990). Gender and race differences in computing attitudes and experience. Social Science Computer Review, 8(1), 42-63.

Bose, R. (2009). Advanced analytics: opportunities and challenges. Industrial Management \& Data Systems, 109(2), $155-172$.

Brooks, P. (2006). Metrics for IT service management. Van Haren. 
Bremser, G. B., Wagner, P. W. (2013). Developing Dashboards for Performance Management. The CPA Journal, July, 62-67.

Chen, H., Chiang, R. H., \& Storey, V. C. (2012). Business intelligence and analytics: From big data to big impact. MIS Quarterly, 36(4), 1165-1188.

Eckerson, W. W. (2011). Performance dashboards: measuring, monitoring, and managing your business. $2^{\text {nd }}$ et., John Wiley \& Sons.

Elias, M., \& Bezerianos, A. (2012). AnnotatingBI visualization dashboards: Needs \& challenges. In Proceedings of the SIGCHI Conference on Human Factors in Computing Systems, ACM, 1641-1650, May.

Few, S. (2013). Information Dashboard Design: Displaying data for at-a-glance monitoring. Analytics Press.

Gefen, D., \& Straub, D. W. (1997). Gender differences in the perception and use of e-mail: An extension to the technology acceptance model. MIS Quarterly, 389-400.

Hatlevik, O. E., Throndsen, I., Loi, M., \& Gudmundsdottir, G. B. (2018). Students' ICT self-efficacy and computer and information literacy: Determinants and relationships. Computers \& Education, 118, 107-119.

Lea, B-R, (2011). Beyond ERP: Enhancing Decision Making through Performance Dashboards and Scorecards, in Readings on Enterprise Resource Planning, Pearson Publishing, 233-271.

Lea, B-R. \& Nah, F. (2013). Usability of Performance Dashboards, Usefulness of Operational and Tactical Support, and Quality of Strategic Support: A Research Framework. in Lecture Notes in Computer Science 8017, Springer-Verlag, 116-123.

Lea, B-R \& Yu, W. (2017). Effectiveness and Efficiency of Enterprise Analytical Dashboard on Decision Support: A Case Study. Pproceedings of the 48th Annual Meeting of the Decision Sciences Institute, 1291893-1 -1291893-12, Washington, DC, November 18-20, 2017.

Lea, B. R., Yu, W. B., \& Min, H. (2018). Data visualization for assessing the biofuel commercialization potential within the business intelligence framework. Journal of Cleaner Production, 188, 921-941.

Loyd, B. H., \& Gressard, C. (1984). The effects of sex, age, and computer experience on computer attitudes. AEDS journal, 18(2), 67-77.

Min, H. (2016). Global Business Analytics Models: Concepts and Applications in Predictive, Healthcare, Supply Chain, and Finance Analytics. Pearson Education.

Morris, M. G., \& Venkatesh, V. (2000). Age differences in technology adoption decisions: Implications for a changing work force. Personnel psychology, 53(2), 375-403.

Moos, D. C., \& Azevedo, R. (2009). Learning with computer-based learning environments: A literature review of computer self-efficacy. Review of Educational Research, 79(2), 576-600.

Parameswaran, S., Kishore, R., \& Li, P. (2015). Within-study measurement invariance of the UTAUT instrument: An assessment with user technology engagement variables. Information \& Management, 52(3), 317-336.

Potosky, D. (2002). A field study of computer efficacy beliefs as an outcome of training: the role of computer playfulness, computer knowledge, and performance during training. Computers in Human Behavior, 18(3), 241-255. 


\section{Issues in Information Systems}

Volume 19, Issue 4, pp. 140-149, 2018

Wells, J. G. (2000). Effects of an on-line computer-mediated communication course, prior computer experience and Internet knowledge, and learning styles on students' Internet attitudes. Journal of industrial teacher education, 37(3), 22-53.

Wang, X., White, L., \& Chen, X. (2015). Big data research for the knowledge economy: past, present, and future. Industrial Management \& Data Systems, 115(9). 